\title{
Article
}

\section{Acquisition of Second Language Grammar Under Incidental Learning Conditions: The Role of Frequency and Working Memory}

Denhovska, Nadiia, Serratrice, Ludovica and Payne, John

Available at http://clok.uclan.ac.uk/11838/

Denhovska, Nadiia ORCID: 0000-0002-3654-5892, Serratrice, Ludovica and Payne, John (2015) Acquisition of Second Language Grammar Under Incidental Learning Conditions: The Role of Frequency and Working Memory. Language Learning, 66 (1). pp. 159-190. ISSN 0023-8333

It is advisable to refer to the publisher's version if you intend to cite from the work. http://dx.doi.org/10.1111/lang.12142

For more information about UCLan's research in this area go to http://www.uclan.ac.uk/researchgroups/ and search for <name of research Group>.

For information about Research generally at UCLan please go to http://www.uclan.ac.uk/research/

All outputs in CLoK are protected by Intellectual Property Rights law, including Copyright law. Copyright, IPR and Moral Rights for the works on this site are retained by the individual authors and/or other copyright owners. Terms and conditions for use of this material are defined in the policies page. 
RUNNING HEAD: Frequency and Implicit Learning of L2 Grammar

\title{
Acquisition of Second Language Grammar Under Incidental Learning Conditions: The Role of Frequency and Working Memory
}

\author{
Nadiia Denhovska, Ludovica Serratrice, and John Payne \\ University of Manchester and University of Central Lancashire
}

Although frequency is recognized as an important factor in second language (L2) acquisition, it has remained relatively under-investigated in terms of its impact on the acquisition of grammatical knowledge under incidental learning conditions. This article reports the results of an experiment where 100 novice adult learners were exposed to a complex noun-adjective agreement pattern in Russian under four incidental learning conditions in which type and token frequency of the stimuli were manipulated. The results show that accuracy was greater in the low type/low token condition and that low token frequency played a more significant role than low type frequency, supporting a "starting small” approach for productive knowledge acquisition. Working memory was differentially involved in production of acquired knowledge in different conditions and not engaged when learning was facilitated by frequency.

Keywords implicit learning; frequency; working memory; L2 grammar

Correspondence concerning this article should be addressed to: Dr. Nadiia Denhovska, University of Central Lancashire, School of Psychology, Fylde Road, Preston, Lancashire, United Kingdom, PR1 2HE, UK. E-mail: ndenhovska@uclan.ac.uk 
To appear in Language Learning, March 2016

\section{Introduction}

Previous research targeting incidental learning has demonstrated that adults can successfully acquire knowledge in such conditions (Leung \& Williams, 2011; Morgan-Short, Sanz, Stainhauer, \& Ullman, 2010; Rebuschat \& Williams, 2012; Williams, 2005). Nevertheless, the general assumption in the literature is that successful L2 acquisition after the critical period, specifically the acquisition of grammatical knowledge, follows an explicit learning mode. That is, the processing of the input is understood to take place with conscious cognitive involvement and with the intention to figure out the underlying regularities (Leow, 2000; Robinson, 2005; Scheffler, 2008; Schmidt, 1993). In order to better understand whether an incidental learning mode can as effectively boost grammatical knowledge acquisition as an explicit learning one, it is important to explore the role of different contributing factors, such as frequency for example, in knowledge acquisition under incidental learning conditions. We begin this study with a brief discussion of the research on incidental learning and on the role of frequency. We then discuss our investigation targeting the acquisition of a noun-adjective agreement pattern in Russian under one explicit learning condition and four different incidental learning conditions, in which type and token frequencies were manipulated.

\section{Background Literature}

Incidental learning conditions are defined as learning environments in which learners are unaware that they are receiving training. This training is followed by a test phase where participants are asked to understand the meaning of sentential stimuli without receiving feedback on their performance (Rebuschat \& Williams, 2012). In contrast, implicit learning is a process during which learners unintentionally derive knowledge from a complex rulegoverned stimulus domain without becoming aware of the knowledge acquired (Reber, 
1967); implicit knowledge is the outcome of such a learning process, described as “unconscious knowledge that subjects are generally not aware of possessing” (Rebuschat \& Williams, 2012, p. 4).

\section{Acquisition of L2 Grammar Under Incidental Learning Conditions}

According to Bley-Vroman’s (2009) Fundamental Difference Hypothesis (FDH), incidental learning processes are no longer available for the acquisition of a L2 grammar in adulthood. The FDH implies that after a certain critical period, a L2 grammar has to be learned explicitly in order to be learned successfully. This hypothesis is supported by research on immigrant adult L2 learners of English who performed worse on grammaticality judgment tests if they had been immersed in the language environment after puberty, compared to those who had been exposed to the L2 before puberty (DeKeyser, 2000; Johnson \& Newport, 1989). Further support emerged from the findings of studies directly comparing the effectiveness of L2 grammatical knowledge acquisition in incidental and explicit modes of learning (Robinson, 1997; Rosa \& O’Neil, 1999). These studies demonstrated that explicit (Rosa \& O’Neil, 1999) or instructed (Robinson, 1997) conditions led to higher levels of knowledge intake.

Nevertheless, research on grammar learning under incidental conditions shows that learners can successfully acquire grammatical knowledge without being explicitly taught grammar rules. In these studies, participants learning an artificial or semi-artificial grammar via incidental exposure perform at above-chance levels on posttests measuring knowledge retention (Rebuschat \& Williams, 2012; Tagarelli, BorgesMota, \& Rebuschat, 2011; Williams, 2005). These studies, however, have generally explored the comprehension domain; very little research so far has focused on the acquisition of productive grammar knowledge under incidental exposure (Brooks \& Kempe, 2013; Hama \& Leow, 2010). A focus on production is important in order to understand how language is acquired in natural settings. One notable exception is the study by Hama and Leow (2010). In this study, the 
authors made various methodological changes (such as including think-aloud protocols and oral presentation of the stimuli) to the study by Williams (2005), in which learners acquired determiner-noun agreement rules (according to animacy and distance) in a semi-artificial language under incidental learning conditions. Specifically, Hama and Leow extended the original study with the addition of a production task. Their results indicated that unaware participants performed significantly above chance in the production of only distance items (both trained and new) but not animacy items. At the same time, other studies have demonstrated that receptive and productive knowledge of some aspects of L2 grammar (gender agreement, in particular) can be acquired to similar levels under incidental and explicit training conditions. For instance, an artificial language study Morgan-Short et al. (2010) demonstrated that although participants in the incidental and explicit learning conditions exhibited different event-related potential (ERP) patterns, both groups showed significant learning effects and “there were no significant group differences” (p. 171).

It is worth stressing, however, that research within the incidental learning paradigm has generally focused on artificial or semi-artificial languages. Very little research has addressed acquisition under incidental exposure to a new, natural language that is unfamiliar to the learners (Chen et al., 2011; Brooks \& Kempe, 2013). Other relatively under-researched areas in L2 acquisition are the role of type and token frequency, and of working memory. In the present study, we address these issues and investigate whether the acquisition of productive knowledge of a grammar pattern in a natural language is differentially affected by the learning condition (explicit vs. incidental), by type and token frequency, and by working memory.

\section{Frequency and L2 Learning}

Studies of first language (L1) development have demonstrated that frequency is a crucial factor in boosting language learning in children, which is primarily incidental (Abbot-Smith, 
Lieven, \& Tomasello, 2004; Brandt, Verhagen, Lieven, \& Tomasello, 2011; Kidd, Lieven, \& Tomasello, 2006, 2010; Lieven \& Tomasello, 2008; Matthews, Lieven, Theakston, \& Tomasello 2005; Tomasello, 2003).The primacy of token frequency has been stressed in relation to exemplar-based learning in L1 acquisition; repeated exposure and use of a given construction leads to the accumulation of a critical mass of tokens. Type frequency comes into play in the generalization of the acquired knowledge to new items and in the abstraction of schemas (Tomasello, 2000, 2008). Similarly, according to Bybee’s $(1985,1988)$ network model, type and token frequency play crucial roles in establishing and maintaining complex morphological representations, where high token frequency facilitates entrenchment and type frequency prompts productivity. Nevertheless, little is known about whether the same principles apply to learning grammar under incidental learning conditions in adults. Researchers who argue for the role of associative and cognitive learning in L2 development believe that frequency impacts L2 learning in the same way as the learning of a L1 (Hulstijn, 2005; N. Ellis, 2002, 2006). However, those studies demonstrating that frequency fosters incidental learning of L2 grammar have focused on languages that are at least partly known to the learners (Lee, 2002). Little so far is known about the acquisition of a natural language grammar by novice adult learners who have never been exposed to the language before, and whether frequency affects L2 knowledge acquisition through incidental exposure similarly to how it influences L1 development.

Frequency is considered by many as an important factor for L2 learning (Gass \& Mackey, 2002; N. Ellis, 2002; Hulstijn, 2005). For instance, as suggested by the AssociativeCognitive CREED model (N. Ellis, 2006), processes that guide L2 acquisition are no different from those that guide the acquisition of any other type of information. According to this hypothesis, high-frequency constructions are learned more easily than low-frequency ones through associative learning mechanisms, and there is ample evidence that humans are 
extremely sensitive to the frequencies of elements that co-occur together in the input ( $\mathrm{N}$. Ellis, 2002; Lieven, 2010; Saffran, 2003; Saffran, Newport, Aslin, Tunick, \& Barrueco, 1997). Similarly, in the artificial-grammar learning paradigm, the "fragment view" approach places a high importance on frequency as a mechanism that fosters the tracking of cooccurrences of items in the input and their storage as fragments in memory. For example, artificial grammar studies have shown that learners are sensitive to the frequency with which certain symbols co-occur in training (Johnstone \& Shanks, 2001; Knowlton \& Squire, 1994; Knowlton, Ramus, \& Squire, 1992; Perruchet \& Pacteau, 1990). Few empirical studies, however, have focused on how frequency impacts the acquisition of an unfamiliar natural L2 grammar through incidental learning (Robinson, 2005).

In the field of L2 learning, previous research has confirmed that frequency positively affects acquisition of L2 vocabulary by adult learners under incidental learning conditions (Hamrick \& Rebuschat, 2013; Rott, 1999). Researchers have also provided evidence that frequency of exposure of adults to the input of a familiar L2 can boost the acquisition of salient grammar forms through incidental learning (Lee, 2002). Robinson (2005) examined how frequency affects acquisition by novice learners of natural language grammar under incidental learning conditions. Japanese speakers were exposed to Samoan and were targeted for the learning of ergative marking rules in transitive sentences. There were nine sentences of different types, each repeated 50 times during training. However, each verb was used only in one context and was thus associated with only one word-order pattern. Participants' performance on grammaticality judgment posttests showed high accuracy on old grammatical sentences, but not on new grammatical and ungrammatical sentences, demonstrating that there was a failure to transfer the knowledge gained during training to novel sentences. Thus, although previous research has shown that frequency has some positive impact on the acquisition of knowledge through incidental exposure, in the present study, we aim to better 
understand how the manipulation of type and token frequency affects the acquisition of productive knowledge of an L2 grammar pattern under incidental learning conditions.

\section{Working Memory and Incidental Learning}

It is important to know how frequency interacts with other factors, such as working memory (WM), which has generally been established as a necessary resource for successful acquisition of language knowledge for both L1 (Adams \& Gathercole, 1995 Morra \& Chamba, 2009) and L2 (Mackey, Philp, Egi, Fujii, \& Tatsumi, 2002; Miyake \& Friedman, 1998; Speciale, Ellis, \& Bywater, 2004). WM plays a crucial role in both the learning and the retrieving of grammatical knowledge, such as gender marking (Kempe, Brooks, \& Kharkhurin, 2010). However, it is not yet known whether WM resources would be differentially involved in the activation of knowledge acquired under incidental learning conditions, in which frequency likely has different facilitating effects.

Research that has investigated the impact of WM on incidental learning (Conway, Baurnschmidt, Huang, \& Pisoni, 2010; Kaufman et al., 2010) using online tasks or posttest measures of the acquisition of knowledge (Brooks \& Kempe, 2013; Tagarelli et al., 2011) found no effect of WM. Yang and Li (2012) explored the neural cognitive mechanisms underlying implicit and explicit learning of artificial grammar sequences. As part of this investigation, they measured participants’ phonological and working memory using a letternumber sequence task and the N-back working memory task, in which participants were asked to press a response button to identify whether the letter presented was identical to a pre-specified letter in a given series of letters. They found that participants' WM differentially affected the two types of artificial grammar learning; WM positively affected performance in grammaticality judgements about the test sequences of the artificial grammar in the explicit learning condition, but not in the incidental learning condition. 
Tagarelli et al. (2011) studied the impact of WM on the acquisition of L2 syntax in incidental and explicit learning conditions. Native speakers of English who had no previous knowledge of German were assigned to one of two groups: incidental or rule-search. They then learned a semi-artificial language consisting of English words and German syntax and had to perform a grammaticality judgement test after training. As a measure of WM, participants completed the Operation Word Span task, in which an equation and a word appeared on the computer screen. Participants had to read the word aloud, indicate whether the equation was correct, and later recall as many words presented as possible. Participants also completed a letter-number ordering task, where they had to repeat previously presented numbers in numerical order and previously presented letters in alphabetical order. The results showed that there was no significant difference between the incidental and rule-search groups on either WM test. Additionally, for the incidental learning group, there was no correlation between accuracy on the grammaticality judgment test and performance on either of the two WM tests. There was, however, a significant positive correlation between the accuracy on the grammaticality judgment tests and participants’ performance on the letter-number ordering task in the rule-search group. WM did not appear to affect the ability to acquire knowledge of L2 syntax under the incidental learning condition, but influenced the learning of L2 syntax in the explicit learning condition.

Similar null effects of WM on knowledge acquisition under incidental learning conditions were found by Brooks and Kempe (2013). In contrast to other studies that focused on the comprehension of artificial languages (Conway et al., 2010; Kaufman et al., 2010; Tagarelli et al., 2011; Yang \& Li, 2012), Brooks and Kempe investigated the acquisition of productive knowledge of Russian gender and case agreement patterns by novice learners through incidental exposure over six sessions. In line with previous research conducted using 
artificial languages, the authors reported that WM was not a significant predictor of knowledge acquisition.

\section{The Current Study}

The present study explores the acquisition of productive knowledge of a noun-adjective agreement pattern in Russian (as in e.g. krasniy volshebnik "red magician”; k krasnomu volshebniku "towards the red magician"), which represents a prime example of the local cooccurrence of inflectional endings in a natural language, through incidental learning by adults. Like Brooks and Kempe (2013), we address the acquisition of grammatical knowledge in a natural language. Previous research that has explored the acquisition of knowledge through incidental learning generally used artificial or semi-artificial languages. It is, however, important to employ a natural language in order to gain a better understanding of how adults acquire a L2 in a natural learning environment.

When focusing on Russian noun-adjective agreement, we manipulated the type and token frequency of feminine and masculine nouns in four different cases: nominative, dative, instrumental, and genitive. In the incidental learning conditions, we adopted the training paradigm generally accepted in the literature in relation to the learning of morphosyntax through incidental exposure, where experimental participants are usually asked to focus on meaning and are not informed about the subsequent testing (Rebuschat \& Williams, 2012; Tagarelli et al., 2011). An explicit learning condition was also included to compare the effectiveness of knowledge acquisition with the incidental learning condition. Previous research has demonstrated that an explicit learning condition is generally more effective for L2 grammar knowledge acquisition than an incidental condition (DeKeyser, 1995; N. Ellis, 1994 Norris \& Ortega, 2000; Robinson, 1997. These studies used metalinguistic explanations of the rule as a method of training in the explicit learning condition. We also provided metalinguistic information about the rule during training in the explicit learning condition 
instead of using a rule-search condition, which allows for a degree of implicitness during learning. Thus, the incidental and explicit learning conditions were intentionally kept distinct in terms of experimental design. This was done in order to make our study more informative for L2 teaching and to bring laboratory research closer to L2 learning in natural settings, where learners are usually taught grammatical rules. In addition, we measured participants’ working memory capacity using complex standardised WM tests to better understand the mediating effect of WM during learning under different incidental conditions. ${ }^{1}$

Therefore, the main aim of this study was to explore how frequency and WM affect the acquisition of productive knowledge of a noun-adjective agreement pattern in Russian under incidental learning conditions. Russian was chosen because, unlike English, it requires overt marking of gender agreement between nouns and adjectives, a novel morphosyntactic pattern for native speakers of English. The questions addressed by the study were the following:

1. Is the acquisition of productive knowledge of a Russian noun-adjective agreement pattern under incidental learning conditions affected by the manipulation of type and token frequency?

2. Is there a correlation between WM capacityand the acquisition of productive knowledge of a Russian noun-adjective agreement pattern under incidental learning conditions?

3. Is there a difference, in terms of productive knowledge acquisition, between incidental and explicit learning conditions? 


\section{Method}

\section{Participants}

Undergraduate students ( $N=100 ; 25$ males, 75 females) were included in the study (18-38 years of age). Participants received course credit or $£ 5$ payment for their participation. Sixtyeight of the participants had some beginner or intermediate knowledge of one or more foreign languages: French ( $n=16$ beginner; $n=7$ intermediate), Spanish ( $n=4$ beginner; $n=6$ intermediate), German ( $n=10$ beginner; $n=2$ intermediate), Urdu ( $n=2$ beginner), Panjabi ( $n=1$ intermediate), Ancient Greek ( $n=2$ beginner), Latin ( $n=2$ beginner), Japanese $(n=2$ beginner), Arabic ( $n=1$ beginner; $n=1$ intermediate), Chinese ( $n=2$ beginner), Welsh ( $n=$ 1 beginner), Swedish ( $n=1$ beginner; $n=1$ intermediate), Italian ( $n=2$ beginner), Dutch ( $n$ $=1$ intermediate), Irish ( $n=1$ beginner), and Afrikaans ( $n=1$ intermediate). The majority of these participants reported themselves as monolinguals and mentioned that they had studied their L2s at school and currently did not use them on a regular basis. None of the participants had ever studied Russian or any other Slavic language, and none of them had any advanced knowledge of a language with grammatical gender agreement, linguistics, or psychology. The participants were randomly allocated to one of the five conditions, for a total of 20 participants in each condition.

\section{Materials}

The materials included Russian words: six animate nouns and four adjectives (shown in full in Appendix S1 in the Supporting Information online), as well as three prepositions ( $k$ "towards," ot "away from,” s "with”) and the particle eto "this.” The stimuli were selected on the basis of imageability and matched for the number of syllables. All the nouns were animate stereotypical characters (e.g., volshebnik “magician”). We used adjectives that could be easily identified in the context of the pictures (e.g., old, black, bald). Nouns contained 2-3 
syllables, and all adjectives were disyllabic. In addition, only nouns and adjectives that fell into the inflectional paradigm of cases represented in Table 1 were selected.

\section{TABLE 1}

The training sentences contained noun-adjective agreement in nominative, dative, instrumental, and genitive cases for singular nouns. The instrumental case was of particular interest, as it creates a pattern of similar endings between the adjective and the noun (e.g. $s$ nizkoy vedmoy "with the short witch”; s krasnim volshebnikom "with the red magician”). It was thus considered to be salient in the context of the other cases and potentially easier to learn through incidental exposure. The other cases were selected on the basis of how easy it would be to create a series of slides to create a short narrative. Each slide contained a picture and a Russian sentence, illustrated in Figure 1 and Table 2.

\section{FIGURE 1}

\section{TABLE 2}

Depending on the incidental learning condition, participants viewed a different number of types and tokens and, thus, a different number of experimental slides. Each type was represented by a story about a feminine or a masculine character that consisted of four slides presented sequentially. The order of story presentation was randomized. A breakdown of experimental materials presented to the participants in each condition is shown in Table 3.

\section{TABLE 3}

\section{Working Memory Tests}

Operation Span (OS) and Reading Span (RS) tests (Unsworth, Heitz, Schrock, \& Engle, 2005) were used as measures of WM. During the OS test, participants were presented with simple arithmetical operations, such as $(2 * 1)+1=3$, and were asked to judge their correctness as quickly as possible by clicking a true or false box on the computer screen. Immediately after each operation was judged, an English letter appeared on the screen, and 
participants were instructed to memorize the letters in the order in which they were presented. The arithmetical problem - letter pairs were presented in sets of 3 to 7 items. After each complete set participants had to recall the English letters in the correct order by ticking the appropriate box on the screen with a mouse click. Trials consisted of 3 sets of each set-size, with the set-sizes ranging from 3 - 7. The order of presentation of each set size was random for each participant. Altogether participants were presented with 75 letters and 75 arithmetical problems. Participants were instructed to keep their accuracy in the arithmetical operations at least $85 \%$, and they received feedback on how many letters they recalled. The test trials were preceded by a set of practice items. During the practice session, the mean time that each participant required to solve an arithmetical operation was recorded by a computer program, which was then used during the presentation of the test trials. If the participants took more than their average time plus 2.5 standard deviations to solve the equation, then the program automatically moved on, and the trial was recorded as an error.

In the RS task, participants were presented with semantically plausible and semantically anomalous English sentences on the computer screen and were asked to judge the semantic plausibility of the sentences by clicking a true or false box on the computer screen. After each sentence was judged, an English letter appeared on the screen, and participants were instructed to memorize the letters in the order they were presented. The procedure for the RS test was similar to that for the OS test. The two WM tasks were obtained from the Attention and WM Lab at Georgia Institute of Technology; the tasks have been used in a number of previous studies (Redick et al., 2012; Turner \& Engle, 1989; Unsworth \& Engle, 2008).

\section{Procedure}

Participants were randomly assigned to one of five conditions: the explicit learning condition or one of the four incidental learning conditions. The experiment consisted of a pretraining 
phase in which participants were administered the two WM tests. In this phase, they also undertook vocabulary learning, which they were tested on. The pretraining phase was followed by a training phase in which participants either received explicit instruction on the noun-adjective agreement rule in the four cases and the two genders or were exposed to varying types and tokens of actual sentences as a function of frequency condition (high type/high token, high type/low token, low type/low token, low type/high token). The test phase immediately followed the training phase, and participants were tested on their productive knowledge of noun-adjective agreement.

\section{Pretraining}

First, participants completed the two WM tasks (OS, RS) via E-Prime 2 (Psychology Software Tools). For the vocabulary test, they were instructed to memorize the six target Russian nouns, four adjectives, three prepositions, and the particle eto (see Appendix S1 in the Supporting Information online) while going through the slides on the computer screen at their own pace. Each slide contained a Russian word (transliterated into the Latin alphabet), its English translation, and a matching picture. The nouns and the adjectives were exclusively of masculine gender and were presented in the singular form and in the nominative case. After the memorization phase, participants completed a vocabulary test. They saw a picture and a transliterated Russian word presented via E-Prime, and had to press 1 ("match”) or 2 ("mismatch") on the keyboard to indicate whether the word matched the picture. After their response, either "Correct” or "Incorrect," together with the overall percentage score, appeared on the computer screen. Participants had to score at least $85 \%$ on the vocabulary test to proceed to the training phase.

\section{Training}

In the practice phase, participants in the incidental learning conditions saw one sequence of pictures with Russian sentences involving a stereotypical character of masculine gender and 
one sequence involving a stereotypical feminine character, like the one represented in Figure 1. Each sequence consisted of four sentences, including a noun-adjective string in four cases (nominative, dative, instrumental, and genitive), and four semantically corresponding pictures. Participants were thus given one example of a story with a character of each gender and were told that the character was of either masculine or feminine gender, but they were not explicitly told about the case-marking pattern. Participants were asked if they correctly understood the motion of the characters depicted in the pictures. Participants were told that in the subsequent training phase, they would view similar stories about similar characters.

During the training phase, participants in the incidental learning conditions were presented similar stories or sequences of slides containing sentences in Russian and pictures depicting actions performed by stereotypical feminine and masculine characters via E-Prime 2. Each story represented the agreement pattern in the four cases and consisted of four slides presented sequentially, for 4,000 milliseconds each, in the following order: nominative, dative, instrumental, and genitive case (see Figure 1). The presentation of the stories was randomized. Overall, the training time in the incidental learning conditions lasted for 5-26 minutes, depending on the frequency condition. Participants received the following instructions: "Now you will see stories about different characters similar to the ones you have just seen. Please, look at the picture, read the sentence to yourself and try to understand its meaning.” Participants were told to sit comfortably in the chair, look at the computer screen, and were reminded that they did not need to do anything else during this task.

Participants in the explicit learning condition were presented with two examples of the noun-adjective agreement in all four cases for each gender together with the translations and the relevant metalinguistic explanation (please see Appendix S2 in the Supporting Information online for the detailed instruction script). They were then given 15 minutes to look through the slides again at their own pace and memorize the agreement rule, having 
been informed that they would be tested on it afterwards. Each slide contained a Russian sentence transliterated into the Latin alphabet with adjectival and noun endings highlighted in bold, an English translation written underneath, and a semantically corresponding picture similar to the ones presented to participants in the incidental learning conditions.

Testing

To test productive knowledge, the participants also completed a gap-fill production task. Here, they saw pictures with Russian sentences similar to the ones they were exposed to during training and had to provide the missing ending of the adjective. There were 30 grammatical Russian sentences in each task. Half of the sentences were old (i.e., seen during training) and half of the sentences were new (i.e., describing new stereotypical characters and consisted of previously unseen nouns and adjectives). The order of presentation of new and old blocks of sentences was counterbalanced among the participants. Participants in the incidental learning conditions were told that they would next see sentences and pictures similar to the ones they had seen previously, whereas participants in the explicit learning condition were told that they would be tested on the previously learned rule.

\section{Debriefing}

Participants completed all tasks in one session, which lasted approximately 60 minutes, and were asked if they had noticed any rules or systematic patterns in the sentences presented to them. If the participant could verbalize the metalinguistic rule of noun-adjective agreement or simply stated that the ending of the word changed depending on the movement of the character or the gender of the character, they were classified as "aware.” If the participant stated that they did not notice anything, they were classified as "unaware.” Based on this classification, there were 28 aware and 52 unaware participants in the incidental learning conditions. However, because investigating the role of awareness in knowledge acquisition was not the focus of the present study, and employing verbal reports for measuring awareness 
was one of its limitations, we do not report separate results for aware and unaware participants.

\section{Results}

\section{Frequency and Production in Incidental Learning Conditions}

Production accuracy was measured for old and new items in the four cases (nominative, dative, instrumental, and genitive) and two genders (feminine and masculine). The overall performance in the production task in all the conditions, including the explicit learning condition, was below chance. A distinction was made between complete production of the adjectival endings (where the full ending was reproduced correctly) and incomplete production (where the ending was partially reproduced). For the incomplete production, a participant received a point if, for instance, instead of providing the complete adjectival ending - aya for the agreement in the feminine gender nominative case, a participant produced an incomplete ending $-a$ or $-y a$. The production accuracy for the complete and incomplete endings is plotted graphically in Figures 2 and 3.

\section{FIGURE 2}

We then conducted statistical analyses comparing production accuracy between the incidental learning conditions. In the incidental learning conditions, both aware and unaware participants were included in the analyses. The data were analysed using logistic regression in R by applying a Generalized Linear Model (GLM) in the R Commander software package (R Development Core Team, 2009). We checked for normality and homogeneity by visual inspections of plots of residuals against fitted values, and we present MCMC ${ }^{1}$-estimated $p$ values that are considered significant at the $\alpha$ levels of .05. To investigate production accuracy of adjectival endings, the following factors were included in the model as fixed effects: Condition, OS Total score, and RS Total score. The Condition factor had four levels

\footnotetext{
${ }^{1}$ MCMC value stands for Markov Chain Monte Carlo estimate of probability
} 
according to the incidental learning conditions. The binomial family of GLM with the logit link function was used because the variable was dichotomous. The low type/low token frequency condition was chosen as a reference category because of its theoretical interest. The variables to be included in the model were selected on the basis of theoretical importance and the Bayesian information criterion (BIC).

\section{FIGURE 3}

\section{Production of Complete Endings}

The analysis targeting the production of complete endings (summarized in Table 4) demonstrated that participants in the low type/low token frequency condition performed significantly better than participants in all other incidental learning conditions. We also conducted separate comparisons between each incidental learning condition using the following model: Condition (fixed effect) and Subject (random effect). A significant difference in production accuracy was found between all the incidental learning conditions, except between low type high token and high type low token frequency conditions. The results of these between-condition comparisons are shown at the bottom of Table 4 .

\section{TABLE 4}

\section{Production of Incomplete Endings}

The analysis targeting the production of incomplete endings (summarized in Table 5) showed that participants in the low type/low token frequency condition performed better than in the high type/high token frequency condition. Separate between-condition analyses (shown at the bottom of Table 5) also demonstrated that in other incidental learning conditions, participants produced endings more accurately than in the high type/high token frequency condition.

TABLE 5

\section{Old Versus New Items in Incidental Learning Conditions}


In addition, the analysis comparing the old and new items in each incidental learning condition demonstrated that participants performed significantly more accurately on old compared to new items in the production of complete endings. The same was not true, however, for the production of incomplete endings. These results are summarized in the first two columns of Table 6 .

\section{TABLE 6}

\section{Production in the Explicit Learning Condition}

To compare the incidental learning conditions with the explicit learning condition, we conducted separate comparisons between the explicit condition and each incidental learning condition through a similar logistic regression analysis using Condition (fixed effect) and Subject (random effect). These results are summarized in the last two columns of Table 6. Overall, participants in the explicit learning condition produced both complete and incomplete endings more accurately than in each incidental learning condition.

\section{WM and L2 Grammar Learning}

Having found a significant positive effect of WM on production accuracy in a logistic regression analysis (see Table 4), we then conducted a series of two-tailed Pearson correlation tests to further explore the relationship between participants' scores on the WM tests and productive knowledge acquisition in each incidental learning condition. Separate correlations were conducted for two scores arising from the WM tests: (a) OS/RS total score, which was calculated for all the letters recalled by participants in the order they were presented, and (b) OS/RS score, which was calculated for all the letters recalled without taking into account the order of recall. These analyses revealed that production accuracy in the explicit learning condition was positively correlated with the OS test scores, whereas production accuracy in the incidental learning conditions positively correlated with the RS test scores (see Table 7). Detailed information about participants’ performance in production 
and their individual differences in WM is provided in Appendix S3 in the Supporting Information online.

\section{TABLE 7}

\section{Discussion}

We investigated the impact of frequency and WM on knowledge acquisition in incidental learning conditions. Following previous research paradigms, we designed conditions in which participants were focused on meaning and were not informed about subsequent testing or given the correct rules; this paradigm is typically used to experimentally test knowledge acquisition through incidental exposure (Rebuschat \& Williams, 2012). Learning taking place under incidental learning conditions is different from both deductive or inductive learning taking place under explicit instruction, where the correct rules are normally presented before or after the examples (DeKeyser, 1995, 2003), and from learning under rule-search conditions, where learners are informed about the rules underlying the input and instructed to figure them out (Tagarelli et al., 2011). In this study, we assume that the morphological forms were learned within a construction (namely, as in This is $X$, or going towards, going with, or going away from constructions), since the learners were directed to the meaning through pictures, and had to apply it to the form expressed by the sentential stimuli, which contained noun-adjective agreement patterns. In addition, our comprehension results (reported in Appendix S4 in the Supporting Information online) suggest that the morphological pattern of noun-adjective agreement may be more susceptible to learning under incidental exposure compared to other kinds of morpho-syntactic information, as it requires a learner to simply notice a changing pattern in input, build associations between two orthographic elements closely co-occurring together, and store them in memory. These results are in line with those reported by Morgan-Short et al. (2010), who focused on the acquisition of an agreement rule in an artificial language. Similar to previous L2 acquisition research, our findings suggest that 
an explicit learning condition is generally more effective for the acquisition of L2 grammatical knowledge than any incidental learning condition (DeKeyser, 1995; N. Ellis, 1994 Hulstijn \& de Graaff, 1994; Norris \& Ortega, 2000; Robinson, 1997. Our results also demonstrate that participants in the explicit learning condition exhibited better knowledge retention in production than participants in the incidental learning conditions.

\section{Frequency and Incidental Learning}

With respect to the role of frequency, our first finding is that, at the initial stages, adults appeared to "start small” in production (that is, our results reflected the incremental learning process, since the learning effect was greatest in the condition, where participants were presented with fewer examples of the pattern, and therefore, a less complex input, i.e. low type/low token frequency), and that token frequency had a more significant effect for productive knowledge acquisition than type frequency. Overall, learners who were exposed to fewer types and fewer tokens exhibited the highest level of accuracy in production among all the incidental learning conditions. Learners exposed to fewer types and higher numbers of tokens exhibited the second highest accuracy rate, as can be seen by the production of incomplete endings results. These results are in line with the notion of "less is more", from the standpoint that in the condition where beginner learners were confronted with a less complex and cognitively demanding input to be processed during incidental exposure, i.e. a small number of types of a given construction repeated less frequently (i.e. low type/low token frequency condition) the knowledge retention effect was stronger and resulted in engaging less cognitive resources, compared to the condition utilizing a more complex input (i.e. high type/high token frequency condition).ur results are also consistent language acquisition studies proposing the primacy of token frequency over type (Newport, 1990; Tomasello, 2000, 2008) and exemplar-based learning assumptions (Braine \& Brooks, 1995; 
Brooks, Tomasello, Dodson, \& Lewis, 1999; N. Ellis, 2002, 2006; Ellis, O’Donnell, \& Romer, 2014; Tomasello, 2000, 2008).

These results are also consistent with cognitive approaches to L2 learning and the event-based view that posits the importance of tokens over types for the categorization of input information (N. Ellis, 2002). They also fit with the implications of some research on artificial language learning, showing that adults learned morphology and meaning better when initially presented with small segments of language rather than the full complex system (Kersten \& Earles, 2001). Similar findings were obtained in a computation modelling study in which a connectionist network was trained to process complex sentences (Elman, 1993). Learning was observed only when it occurred incrementally starting with a small number of data segments, and failed when the network was presented with the entire dataset at once. In our experiment those learners who were exposed to few examples (low type/low token frequency condition) could retain and produce the knowledge more accurately, compared to those who had been exposed to a higher number of examples that included different word types (e.g., high type/high token frequency condition). Our findings show that beginner adult learners, when exposed to a novel grammatical pattern, "start small” in the acquisition of productive grammatical knowledge, guided by few examples in the input. Nevertheless, it is worth noting that, since the present study was a controlled laboratory experiment, the number of types and tokens was considerably smaller than what a child or an adult is typically exposed to in natural settings.

Another explanation could be that the acquisition of a grammatical pattern in beginner adult learners is based on memorization. Taraban (2004) showed that while learning an artificial grammar, adults tend to memorize rather than regularize the structure. Hudson Kam and Newport (2005) also found that, unlike children, adults exposed to inconsistent input in an artificial grammar tended not to regularize the language. Robinson (2005) reported that 
participants accepted chunks of ungrammatical letter strings presented with high frequency as correct, which may imply that high frequency items may appear more salient during the process of forming memory representations. Thus, as suggested by a fragment-view approach, learners track the frequency of the items co-occurring in the input and store them in memory as fragments (Johnstone \& Shanks, 2001; Knowlton et al., 1992; Knowlton \& Squire, 1994; Perruchet \& Pacteau, 1990). Such piecemeal memorization is present in our findings: Learners started with the production of an incomplete ending indicating the knowledge of a given agreement pattern before producing a complete morphological form (e.g., incomplete form - $a$ before complete ending -aya). In addition, the production of complete endings (the full morphological form) was better for the trained (old) rather than the new items. However, the learners were able to generalize the knowledge acquired in the incidental learning conditions when producing an incomplete morphological form indicating gender and case agreement (incomplete endings). Thus, it could be the case that, because productive knowledge acquisition is a more cognitively demanding task, a learner would memorize small chunks of information exemplified by frequently occurring tokens. In contrast, in the comprehension task, where participants were asked to perform a recognition task, accuracy was at ceiling (see Appendix S4 in the Supporting Information online).

\section{Working Memory and Incidental Learning}

The second finding was the relationship between WM production accuracy in learners acquiring grammar knowledge through incidental exposure. This relationship was found in the condition in which the learner was confronted by a complex system of types of the agreement rule as a function of gender and case (i.e., high type/high token frequency condition). However, no association with WM was found in the condition in which frequency facilitated learning (i.e., low type/low token frequency condition); the learners in this condition performed best when compared to all other incidental learning conditions. These 
findings are in line with previous research demonstrating that verbal WM is involved in the learning of words through incidental exposure in the absence of other facilitating factors, such as visual cues (Duyck, Szmalec, Kemps, \& Vandierendonck, 2003). Similarly, the study by Misyak and Christiansen (2012) explored the relationship between statistical learning of adjacent and nonadjacent dependencies and verbal working memory, and also found a positive correlation between performance and WM. The absence of the WM relationship in the low type/low token frequency condition of our study could therefore, perhaps, be explained by the contributing effect of frequency to learning under incidental exposure, i.e. low number of types presented with low frequency created a less complex input for a learner to processes, without having a need to engage cognitive resources.

Moreover, our findings suggest that different types of WM may be involved in knowledge acquisition under incidental and explicit learning conditions. In the present study, learners in the incidental learning conditions were acquiring grammar together with meaning, and thus their production scores correlated with the RS test scores. On the other hand, learners in the explicit learning condition were memorizing the grammar rule, and thus their production scores correlated with the OS scores. This fits with previous studies on the acquisition of grammatical knowledge through explicit and incidental learning, where participants’ performance on posttests in the explicit learning (rule-search) condition correlated with OS scores (Tagarelli et al., 2011), and research on sentence processing and reading in adult L2 learners showing correlations with RS scores (Alptekin \& Ercetin, 2009; Harrington \& Sawyer, 1992; Jeeser, 2007; Juffs, 2004). Different aspects of WM and of executive function may be engaged in the processing of information from different domains of L1 and L2 (Linck et al., 2013). Although relatively little is yet known about how these different aspects of WM and of executive function are involved in linguistic processing, it could be assumed that the processes of maintenance, updating, and shifting (Miyake \& 
Friedman, 2012; Miyake et al., 1999) may be relevant for the present case of knowledge acquisition under the explicit learning condition. The association with the OS scores may be an indication of the involvement of these processes, and the correlation with the RS scores may indicate that procedural processes are taking place. As suggested by MacDonald and Christiansen (2002), RS tasks tap into experience-based language processing skills in addition to memory.

\section{Theoretical Implications}

When it comes to incidental learning, our findings are consistent with the assumption that L2 adult learners are guided by the same principles of associative and cognitive learning as L1 learners, with frequency being a crucial mechanism of learning, as suggested by N. Ellis’s (2006) Associative-Cognitive CREED model. Also, according to Bybee’s network model of the acquisition of complex morphology $(1985,1988)$, both type frequency (understood as the frequency of a morphological pattern) and token frequency (the frequency of exemplars) play an important role in establishing and maintaining representations of the newly acquired associations. High frequency morphosyntactic structures become more entrenched and easier to access as a whole; we did indeed report a better learning effect in production in the high token condition, where learners were exposed to fewer types, than in the conditions with high type frequency (Bybee, 1985; Hooper, 1976). Similar to research by Ellis et al. (2014), entrenchment guided by high token frequency of a particular item occurring within a construction (as evidenced in our incomplete production data) helped adults to access it more easily.

However, contrary to Bybee’s proposal, in this experiment, high type frequency did not increase productivity by strengthening the learned associations and increasing their chances of being applied to new items in production, since generally a poorer performance was found in the high type frequency conditions. Also in contrast to our findings, 
McDonough and Kim (2009), who investigated the role of type frequency (high vs. low) in the structural priming of wh- questions in adult L2 learners of English, reported that learners in the high type condition produced a higher proportion of correct wh- questions than learners in the low type condition. One possible reason for the discrepancy between our findings and those of McDonough and Kim is that in their study participants already possessed some knowledge of English, as they were L2 learners with 7 to 17 years of formal instruction. Thus it appears that, at least in our study focusing on beginner learners, acquisition of productive knowledge of the noun-adjective agreement pattern was based on memorization and followed the trend of piecemeal exemplar-based learning, with token frequency playing a more important role than type frequency (N. Ellis, 2002; Tomasello, 2000, 2008). This, however, may be happening only in the initial stages of learning. In the later stages, when the representations are formed and construction schemas become entrenched, type frequency may come into play as a factor that facilitates abstraction and generalization of the newly acquired knowledge to new items.

As for the asymmetry of the frequency effect in comprehension and production, this may have to do with the general asymmetry between receptive and productive levels of knowledge (ceiling effect in comprehension but below-chance performance in production) in all the incidental learning conditions. This asymmetry in frequency effects in receptive and productive knowledge acquisition could be explained by the assumption that comprehension precedes production in language acquisition (Clark \& Hecht, 1982; Fraser, Bellugi, \& Brown, 1963; DeKeyser \& Sokalski, 1996; Winitz, Sanciers, \& Kort, 1981). At the same time, such an asymmetry between production and comprehension is also qualified by the engagement of WM in incidental learning conditions with different involvement of frequency. Our findings suggest that the impact of frequency is more important for productive knowledge acquisition through incidental exposure, which is more cognitively demanding than the acquisition of 
receptive knowledge, and that frequency appears to boost learning in such a way that a learner does not have a need to extensively engage working memory resources.. In contrast to previous studies focusing on comprehension following exposure to novel sequences or to artificial languages (Conway et al., 2010; Kaufman et al., 2010; Tagarelli et al., 2011) and to findings by Brooks and Kempe (2013) investigating productive knowledge acquisition in a natural language as measured after six learning sessions, beginner learners (exposed to a novel pattern in one session) relied on their WM during production in the present study. The correlation with WM found in the present research may be explained by the nature of natural language learning. During such learning, access to lexical meaning would take place, which implicates the involvement "of declarative memory for words and events," which critically distinguishes artificial language learning from acquisition of a natural language (Robinson, 2010, p. 260). Our findings are also in line with the argument put forward by Kaufman et al. (2010) suggesting that a learner might resort to WM only at the initial stages of learning under incidental learning conditions. Since our participants were tested after a single hourlong session, it would be desirable for future research to conduct a longitudinal study in order to investigate whether a learner may still resort to WM after multiple exposures and whether performance on production would improve.

\section{Conclusion}

When acquiring productive knowledge under implicit “focus on meaning” instruction, during which learners do not receive information about the rules the input (N. Ellis, 1994; Norris \& Ortega, 2000), frequency of examples in the input and learners’ WM are significant contributors to building such knowledge. As our study suggests, if there are fewer examples of the target grammatical structure in the input, learners identify this structure more quickly and are thus able to produce it with greater accuracy when compared to learners initially presented with many representative examples of the target structure. In addition, if these few 
examples are repeated frequently throughout the learning practices, it would positively influence the acquisition of productive knowledge in beginner adult learners. Also, in the initial stages of learning, learners with better WM capacity are more likely to produce the target morphological form correctly. Future research could look into this issue in more ecologically valid settings, such as language classrooms, by exploring how an implicit "focus on meaning” instruction together with the usage of different numbers of representative examples of the grammar rule in the input would affect students' learning. A longitudinal study in this respect would be desirable and informative, as it would shed light on the levels of productive knowledge acquired across an extended period of time and would clarify the relative involvement of $\mathrm{WM}$ at different stages of the learning process.

Final revised version accepted 16 March 2015

\section{Notes}

1 We also measured reaction times (RTs) in the comprehension task, on the basis that implicit knowledge is automatic and easy to activate (Shiffrin \& Schneider, 1977) and following previous research that has identified timed tasks as suitable measures for implicit knowledge (R. Ellis, 2005). Because participants in all conditions performed at ceiling in comprehension, and no statistically significant difference was found between implicit and explicit learning for comprehension accuracy $(p=.10)$, comprehension RTs $(p=.37)$, or performance on new versus old items, comprehension data will not be discussed further. However, comprehension data are provided in Appendix S4 in the Supporting Information online. 


\section{References}

Abbot-Smith, K., Lieven, E., \& Tomasello, M. (2004). Training 2;6-year-olds to produce the transitive construction: the role of frequency, semantic similarity and shared syntactic distribution. Developmental science, 7, 48-55. doi:10.1111/j.1467-7687.2004.00322.x

Adams, A.M., \& Gathercole, S. (1995). Phonological working memory and speech production in preschool children. Journal of Speech, Language, and Hearing Research, 38, 403-414. doi:10.1044/jshr.3802.403

Alptekin, C, \& Ercetin, G. (2009). Assessing the relationship of WM to L2 reading: Does the nature of comprehension process and reading span task make a difference? System, 37, 627-639. doi:10.1016/j.system.2009.09.007

Bley-Vroman, R. (2009). The evolving context of the fundamental difference hypothesis. Studies in Second Language Acquisition, 31, 175-198. doi:10.1017/S0272263109090275

Braine, M., \& Brooks, P. (1995). Verb argument structure and the problem of avoiding an overgeneral grammar. In M. Tomasello \& W. E. Merriman (Eds.), Beyond names for things: Young children's acquisition of verbs (pp. 352-376). Hillsdale, NJ: Erlbaum.

Brandt, S., Verhagen, A., Lieven, E., \& Tomasello, M. (2011). German children’s productivity with simple transitive and complement-clause constructions: Testing the effects of frequency and variability. Cognitive Linguistics, 22, 325-357. doi:10.1515/cogl.2011.013

Brooks, P., \& Kempe, V. (2013). Individual differences in adult foreign language learning: The mediating effect of metalinguistic awareness. Memory \& Cognition, 41, 281-296. doi:10.3758/s13421-012-0262-9 
Brooks, P., Tomasello, M., Dodson, K., \& Lewis, L. (1999). Young children’s overgeneralizations with fixed transitivity verbs. Child Development, 70, 1325-1337. doi:10.1111/1467-8624.00097

Bybee, J. (1985). Morphology: A study of the relation between meaning and form. Philadelphia: John Benjamins.

Bybee, J. (1988). Morphology as lexical organization. In M. Hammond \& M. Noonan (Eds.), Theoretical morphology (pp. 119-141). San Diego, CA: Academic Press.

Chen, W., Guo, X., Tang, J., Zhu, L., Yang, Z., \& Dienes, Z., (2011). Unconscious structural knowledge of form-meaning connections. Consciousness and Cognition, 20, 17511760. doi:10.1016/j.concog.2011.03.003

Clark, E., \& Hecht, B. (1982). Learning to coin agent and instrument nouns. Cognition, 12, 1-24. doi:10.1016/0010-0277(82)90027-0

Conway, C., Baurnschmidt, A., Huang, S., \& Pisoni, D. (2010). Implicit statistical learning in language processing: Word predictability is the key. Cognition, 114, 356-371. doi:10.1016/j.cognition.2009.10.009

DeKeyser, R. (1995). Learning second language grammar rules: An experiment with a miniature linguistic system. Studies in Second Language Acquisition, 17, 379-410. doi:10.1017/S027226310001425X

DeKeyser, R. (2000). The robustness of critical period effects in second language acquisition. Studies in Second Language Acquisition, 22, 499-533.

DeKeyser, R. (2003) Implicit and explicit learning. In C. J. Doughty \& M. J. Long (Eds.), Handbook of second language acquisition (pp. 313-348). Oxford, MA: Blackwell.

DeKeyser, R., \& Sokalski, K. (1996). The differential role of comprehension and production practice. Language Learning, 46, 613-642. doi:10.1111/j.1467-1770.1996.tb01354.x 
Duyck, W., Szmalec, A., Kemps, E., \& Vandierendonck, A. (2003). Verbal WM is involved in associative word learning unless visual codes are available. Journal of Memory and Language, 48, 527-541. doi:10.1016/S0749-596X(02)00533-8

Ellis, N. C. (1994). Implicit and explicit language learning: An overview. In N. C. Ellis (Ed.), Implicit and explicit learning of languages (pp. 1-32). San Diego, CA: Academic Press.

Ellis, N. (2002). Frequency effects in language processing: A review with implications for theories of implicit and explicit language acquisition. Studies in Second Language Acquisition, 24, 143-188. doi:10.1017/S0272263102002024

Ellis, N. (2006). Cognitive perspectives on SLA: The associative-cognitive CREED. AILA Review, 19, 100-121. doi:10.1075/aila.19.08ell

Ellis, N., O’Donnell, M., \& Romer, U. (2014). The processing of verb-argument constructions is sensitive to form, function, frequency, contingency and prototypicality. Cognitive Linguistics, 25, 55-98. doi:10.1515/cog-2013-0031

Ellis, R. (2005). Measuring implicit and explicit knowledge of a second language: A psychometric study. Studies in Second Language Acquisition, 27, 141-172. doi:10.1017/S0272263105050096

Elman, J. (1993). Learning and development in neural networks: The importance of starting small. Cognition, 48, 71-99. doi:10.1016/0010-0277(93)90058-4

Fraser, C., Bellugi, U., \& Brown, R. (1963). Control of grammar in imitation, comprehension, and production. Journal of Verbal Learning and Verbal Behavior, 2, 121-135. doi:10.1016/S0022-5371(63)80076-6

Gass, S., \& Mackey, A. (2002). Frequency effects and second language acquisition. Studies in Second Language Acquisition, 24, 249-260. doi:10.1017/S0272263102002097 
Hama, M., \& Leow, R. P. (2010). Learning without awareness revisited. Studies in Second Language Acquisition, 32, 465-491. doi:10.1017/S0272263110000045

Hamrick, P., \& Rebuschat, P. (2013). Frequency effects, learning conditions, and the development of the implicit and explicit knowledge. In J. Connor-Linton \& L. Amoroso (Eds.), Measured language: Quantitative approaches to acquisition, assessment, processing, and variation (pp.1-24). Washington, D.C.: Georgetown University Press.

Harrington, M., \& Sawyer, M. (1992). L2 WM capacity and L2 reading skill. Studies in Second Language Acquisition, 14, 25-38. doi:10.1017/S0272263100010457

Hooper, J. (1976). Word frequency in lexical diffusion and the source of morphophonological change. In W. Christie (Ed.), Current progress in historical linguistics (pp. 96-105). Amsterdam: North-Holland.

Hudson Kam, C. L., \& Newport, E. L. (2005). Regularizing unpredictable variation: The roles of adult and child learners in language formation and change. Language Learning and Development, 1, 151-195. doi:10.1207/s15473341lld0102_3

Hulstijn, J. (2005). Theoretical and empirical issues in the study of implicit and explicit second-language learning. Studies in Second Language Acquisition, 27, 129-140. doi:10.1017/S0272263105050084

Hulstijn, J., \& de Graaff, R. (1994). Under what conditions does explicit knowledge of a second language facilitate the acquisition of implicit knowledge? A research proposal. AILA Review, 11, 97-112.

Jeeser, M. (2007). Learner-based factors in L2 reading comprehension and processing grammatical form: Topic familiarity and WM. Language Learning, 57, 229-270. doi:10.1111/j.1467-9922.2007.00408.x 
Johnson, J. S., \& Newport, E. L. (1989). Critical period effects in second language learning: The influence of maturational state on the acquisition of English as a second language. Cognition Psychology, 21, 60-99. doi:10.1016/0010-0285(89)90003-0 Johnstone, T., \& Shanks, D. (2001). Abstractionist and processing accounts of implicit learning. Cognitive Psychology, 42, 61-112. doi:10.1006/cogp.2000.0743

Juffs, A. (2004). Representation, processing and WM in a second language. Transactions of the Philological Society, 102, 199-225. doi:10.1111/j.0079-1636.2004.00135.x

Kaufman, S., Deyoung, C., Gray, J., Jiménez, L., Brown, J., \& Mackintosh, N. (2010). Implicit learning as an ability. Cognition, 116, 321-340. doi:10.1016/j.cognition.2010.05.011

Kempe, V., Brooks, P., \& Kharkhurin, A. (2010). Cognitive predictors of generalization of Russian grammatical gender categories. Language Learning, 60, 127-153. doi:10.1111/j.1467-9922.2009.00553.x

Kersten, A., \& Earles, J., (2001). Less really is more for adults learning a miniature artificial language. Journal of Memory and Language, 44, 250-273. doi:10.1006/jmla.2000.2751

Kidd, E., Lieven, E., \& Tomasello, M. (2006). Examining the role of lexical frequency in children's acquisition and processing of sentential complements. Cognitive Development, 21, 93-107. doi:10.1016/j.cogdev.2006.01.006

Kidd, E., Lieven, E., \& Tomasello, M. (2010). Lexical frequency and exemplar- based learning effects in language acquisition: Evidence from sentential complements. Language Sciences, 32, 132-142. doi:10.1016/j.langsci.2009.05.002

Knowlton, B., Ramus S. J., \& Squire, L. R. (1992). Intact artificial grammar learning in amnesia: Dissociation of classification learning and explicit memory for specific 
instances. Psychological Science, 3, 172-179. doi:10.1111/j.1467-

9280.1992.tb00021.x

Knowlton, B., \& Squire, L. (1994). The information acquired during artificial grammar learning. Journal of Experimental Psychology: Learning, Memory, and Cognition, 20, 79-91. doi:10.1037/0278-7393.20.1.79

Lee, J. (2002). The incidental acquisition of Spanish. Studies in Second Language Acquisition, 24, 55-80.

Leow, R. (2000). A study of the role of awareness in foreign language behavior. Studies in Second Language Acquisition, 22, 557-584.

Leung, J. \& Williams, J. (2011). The implicit learning of mappings between forms and contextually derived meanings. Studies in Second Language Acquisition, 33, 33-55. doi:10.1017/S0272263110000525

Lieven, E. (2010). Input and first language acquisition: Evaluating the role of frequency. Lingua, 120, 2546-2556. doi:10.1016/j.lingua.2010.06.005

Lieven, E., \& Tomasello, M. (2008). Children's first language acquisition from a usage-based perspective. In P. Robinson \& N. Ellis (Eds.), Handbook of cognitive linguistics and second language acquisition (pp. 168-196). New York: Routledge.

Linck, J.A., Hughes, M.M., Campbell, S.G., Silbert, N.H., Tare, M., Jackson, S.R., Doughty, C. J. (2013). Hi-LAB: A new measure of aptitude for high-level language proficiency. Language Learning, 63, 530-566. doi:10.1111/lang.12011

Mackey, A., Philp, J., Egi, T., Fujii, A., \& Tatsumi, T. (2002). Individual differences in working memory, noticing interactional feedback and L2 development. In P. Robinson (Ed.), Individual differences and instructed language learning (pp. 181209). Philadelphia: John Benjamins. 
Matthews, D., Lieven E., Theakston, A., \& Tomasello, M. (2005). The role of frequency in the acquisition of English word order. Cognitive Development, 20, 121-136. doi:10.1016/j.cogdev.2004.08.001

MacDonald, M., \& Christiansen, M. (2002). Reassessing working memory: Comment on Just and Carpenter (1992) and Waters and Caplan (1996). Psychological Review, 109, 3554. doi:10.1037/0033-295X.109.1.35McDonough, K., \& Kim, Y. (2009). Syntactic priming, type frequency, and EFL learners' production of Wh-questions. The Modern Language Journal, 93, 386-398. doi:10.1111/j.1540-4781.2009.00897.x

Misyak, J., \& Christiansen, M. (2012). Statistical learning and language: An individual difference study. Language Learning, 69, 302-331. doi:10.1111/j.14679922.2010.00626.x

Miyake, A., \& Friedman, N. (1998). Individual differences in second language proficiency: Working memory as "language aptitude”. In A. F. Healy \& L. E. Bourne (Eds.), Foreign language learning: Psycholinguistic studies on training and retention (pp. 339-364). Mahwah, NJ: Lawrence Erlbaum.

Miyake, A., \& Friedman, N. (2012). The nature and organization of individual differences in executive functions: Four general conclusions. Current Directions in Psychological Science, 21, 8-14. doi:10.1177/0963721411429458

Miyake, A., Friedman, N., Emerson, M., Witzki, A., Howerter, A., \& Wager, T. (1999). The unity and diversity of executive functions and their contributions to complex "frontal lobe” tasks: A latent variable analysis. Cognitive Psychology, 41, 49-100. doi:10.1006/cogp.1999.0734

Morgan-Short, K., Sanz, C., Stainhauer, K., \& Ullman, M. T. (2010). Second language acquisition of gender agreement in explicit and implicit training conditions: An event- 
related potential study. Language Learning, 60, 154-193. doi:10.1111/j.14679922.2009.00554.x

Morra, S., \& Camba, R. (2009). Vocabulary learning in primary school children: Working memory and long-term memory components. Journal of Experimental Child Psychology, 104, 156-178. doi:10.1016/j.jecp.2009.03.007

Newport, E. (1990). Maturational constraints on language learning. Cognitive Science, 14, 11-28. doi:10.1207/s15516709cog1401_2

Norris, J., \& Ortega, L. (2000). Effectiveness of L2 instruction: A research synthesis and quantitative meta-analysis. Language Learning, 50, 417-528. doi:10.1111/00238333.001360

Perruchet, P., \& Pacteau, C. (1990). Synthetic grammar learning: Implicit rule abstraction or explicit fragmentary knowledge? Journal of Experimental Psychology: General, 119, 264-275. doi:10.1037/0096-3445.119.3.264

Reber, A. (1967). Implicit learning of artificial grammars. Journal of Verbal Learning and Verbal Behavior, 6, 317-327. doi:10.1016/S0022-5371(67)80149-X

Rebuschat, P., \& Williams, J. (2012). Implicit and explicit knowledge in second language acquisition. Applied Psycholinguistics, 33, 1-28. doi:10.1017/S0142716411000580

Redick, T. S., Broadway, J. M., Meier, M. E., Kuriakose, P. S., Unsworth, N., Kane, M. J., \& Engle, R. W. (2012). Measuring WM capacity with automated complex span tasks. European Journal of Psychological Assessment, 28, 164-171. doi:10.1027/1015$5759 / \mathrm{a} 000123$

Robinson, P. (1997). Generalizability and automaticity of second language learning under implicit, incidental, enhanced, and instructed conditions. Studies in Second Language Acquisition, 19, 223-247. 
Robinson, P. (2005). Cognitive abilities, chunk-strength, and frequency effects in implicit artificial grammar and incidental L2 learning: replications of Reber, Walkenfeld, and Hernstadt (1991) and Knowlton, and Squire (1996) and their relevance for SLA. Studies in Second Language Acquisition, 27, 235-268.

doi:10.1017/S0272263105050126

Robinson, P. (2010). Implicit artificial grammar and incidental natural second language learning: How comparable are they? Language Learning, 60, 245-263. doi:10.1111/j.1467-9922.2010.00608.x

Rosa, E., \& O’Neill, M. (1999). Explicitness, intake and the issue of awareness: Another piece to the puzzle. Studies in Second Language Acquisition, 2, 511-556.

Rott, S. (1999). The effect of exposure frequency on intermediate language learners' incidental vocabulary acquisition and retention through reading. Studies in Second Language Acquisition, 21, 589-619.

Saffran, J. (2003). Statistical language learning: Mechanisms and constraints. Current Directions in Psychological Science, 12, 110-114. doi:10.1111/1467-8721.01243

Saffran, J., Newport, E., Aslin, R., Tunick, R., \& Barrueco, S. (1997). Incidental language learning: Listening (and learning) out of the corner of your ear. Psychological Science, 8, 101-105. doi:10.1111/j.1467-9280.1997.tb00690.x

Scheffler, P. (2008). The natural approach to adult learning and teaching of L2 grammar. International Review of Applied Linguistics in Language Teaching, 46, 289-313. doi:10.1515/IRAL.2008.013

Schmidt, R. (1993). Awareness and second language acquisition. Annual Review of Applied Linguistics, 13, 206-226. doi:10.1017/S0267190500002476 
Shiffrin, R, \& Schneider, W. (1977). Controlled and automatic human information processing: II Perceptual learning, automatic attending and general theory. Psychological Review, 84, 127-190. doi:10.1037/0033-295X.84.2.127

Speciale, G., Ellis, N., \& Bywater, T (2004). Phonological sequence learning and short-term store capacity determine second language vocabulary acquisition. Applied Psycholinguistics, 25, 293-321. doi:10.1017/S0142716404001146

Tagarelli, K. M., BorgesMota, M., \& Rebuschat, P. (2011). The role of working memory in the implicit and explicit language learning. In L. Carlson, C. Holscher, \& T. Shipley (Eds.), Proceedings of the 33rd Annual Conference of the Cognitive Science Society (pp. 2061-2066). Austin, TX: Cognitive Science Society.

Taraban, R. (2004). Drawing learners’ attention to syntactic context aids gender-like category induction. Journal of Memory and language, 51, 202-216. doi:10.1016/j.jml.2004.03.005

Tomasello, M. (2000). The item-based nature of children's early syntactic development. Trends in Cognitive Sciences, 4, 156-163. doi:10.1016/S1364-6613(00)01462-5

Tomasello, M. (2003). Constructing a language : A usage-based theory of language acquisition. Cambridge: Harvard University Press.

Tomasello, M. (2008). Origins of human communication. Cambridge: The MIT Press.

Turner, M. L., \& Engle, R. W. (1989). Is WM capacity task dependent? Journal of Memory \& Language, 28, 127-154. doi:10.1016/0749-596X(89)90040-5

Unsworth, N., \& Engle, R.W. (2008). Speed and accuracy of accessing information in WM: An individual differences investigation of focus switching. Journal of Experimental Psychology: Learning, Memory, and Cognition, 34, 616-630. doi:10.1037/02787393.34.3.616. 
Unsworth, N., Heitz, R. P., Schrock, J. C., \& Engle, R. W. (2005). An automated version of the operation span task. Behavior Research Methods, 37, 498-505. doi:10.3758/BF03192720

Williams, J. (2005). Learning without awareness. Studies in Second Language Acquisition, 27, 269-304. doi:10.1017/S0272263105050138

Winitz, H., Sanciers, R., \& Kort, J. (1981). Comprehension and production of the /z/ plural allomorph. Journal of Psycholinguistics Research, 10, 259-271. doi:10.1007/BF01067507

Yang, J., \& Li, P. (2012). Brain networks of explicit and implicit learning. PLOSONE, 7, 19. doi:10.1371/journal.pone.0042993

\section{Supporting Information}

Additional Supporting Information may be found in the online version of this article at the publisher's website:

Appendix S1. Stimuli Used in the Current Study.

Appendix S2. Instructions Script for the Explicit Learning Condition.

Appendix S3. Descriptive Statistics for Participants' Performance in Production and WM Tasks.

Appendix S4. Participants’ Performance in the Comprehension Task. 
Table 1 Case-marking paradigm for adjectives and nouns in feminine and masculine genders in Russian

\begin{tabular}{llllll}
\hline \multirow{2}{*}{ Case } & \multicolumn{2}{c}{ Masculine gender } & & \multicolumn{2}{c}{ Feminine gender } \\
\cline { 2 - 3 } \cline { 5 - 6 } & Adjective & Noun & & Adjective & Noun \\
\hline Nominative & $-\mathrm{iy}$ & $-\varnothing$ & & - aya & $-\mathrm{a}$ \\
Dative & $-\mathrm{omu}$ & $-\mathrm{u}$ & & - oy & $-\mathrm{e}$ \\
Instrumental & $-\mathrm{im}$ & $-\mathrm{om}$ & & - oy & $-\mathrm{oy}$ \\
Genitive & - ogo & $-\mathrm{a}$ & & - oy & $-\mathrm{i}$ \\
\hline
\end{tabular}

Note. Ø indicates no overt marking. 
Table 2 Examples of training sentences presented to participants

\begin{tabular}{|c|c|c|}
\hline Case & Masculine & Feminine \\
\hline \multirow[t]{4}{*}{ Nominative } & Eto krasniy volshebnik. & Eto nizkaya vedma. \\
\hline & This [Ø-copula] red [MASC.NOM] & This Ø-copula short [FEM.NOM] witch \\
\hline & magician [MASC.NOM]. & [FEM.NOM]. \\
\hline & This is a red magician. & This is a short witch. \\
\hline \multirow[t]{4}{*}{ Dative } & Idu k krasnomu volshebniku. & Idu k nizkoy vedme. \\
\hline & I am going towards red [masc.dat] & I am going towards short [FEM.DAT] \\
\hline & magician [MASC.DAT]. & witch [FEM.DAT] \\
\hline & I am going towards the red magician. & I am going towards the short witch. \\
\hline \multirow[t]{4}{*}{ Instrumental } & Idu s krasnim volshebnikom. & Idu s nizkoy vedmoy. \\
\hline & I am going with red [MASC.INST] & I am going with short [FEM.INST] \\
\hline & magician [MASC.INST]. & witch [FEM.INST]. \\
\hline & I am going with the red magician. & I am going with the short witch. \\
\hline \multirow[t]{4}{*}{ Genitive } & Idu ot krasnogo volshebnika. & Idu ot nizkoy vedmi. \\
\hline & I am going away from red & I am going away from short \\
\hline & [MASC.GEN] magician [MASC.GEN]. & [FEM.GEN] witch [FEM.GEN]. \\
\hline & $\begin{array}{l}\text { I am going away from the red } \\
\text { magician }\end{array}$ & I am going away from the short witch \\
\hline
\end{tabular}

Note. Morphological endings are boldfaced in the table; however, no typographical enhancement was used in the training and testing materials. 
Table 3 Distribution of types and tokens in the incidental learning conditions

\begin{tabular}{lccccc}
\hline Frequency condition & Feminine & Masculine & Cases & Repetitions & Slides \\
\hline High type/high token & 7 types & 7 types & 4 cases & 7 times & 392 \\
High type/low token & 7 types & 7 types & 4 cases & 3 times & 168 \\
Low type/high token & 3 types & 3 types & 4 cases & 7 times & 168 \\
Low type/low token & 3 types & 3 types & 4 cases & 3 times & 72 \\
\hline
\end{tabular}


Table 4 Summary of the logistic regression analysis for the production of complete endings

\begin{tabular}{lccc}
\hline Variable & Estimate & $S E$ & Wald $z$ \\
\hline (Intercept) & -3.30 & 0.40 & $-8.27^{* * *}$ \\
Low type/low token vs. Low type/high token & -0.36 & 0.15 & $-2.37^{*}$ \\
Low type/low token vs. High type/low token & -0.29 & 0.15 & -1.88 \\
Low type/low token vs. High type/high token & -1.01 & 0.17 & $-5.63^{* * *}$ \\
Operation Span total score & 0.01 & 0.01 & 1.87 \\
Reading Span total score & 0.02 & 0.01 & $3.49^{* * *}$ \\
Between-condition comparisons & & & \\
High type/high token vs. Low type/high token & 0.77 & 0.19 & $4.11^{* * *}$ \\
High type/high token vs. High type/low token & 0.31 & 0.11 & $2.90^{* *}$ \\
Low type/high token vs. High type/low token & -0.13 & 0.17 & -0.79 \\
\hline
\end{tabular}

Note. ${ }^{*} p<.05,{ }^{* *} p<.01,{ }^{* * *} p<.001 . \mathrm{SE}=$ standard error. 
Table 5 Summary of the logistic regression analysis for the production of incomplete endings

\begin{tabular}{lccc}
\hline Variable & Estimate & $S E$ & Wald $z$ \\
\hline (Intercept) & -2.24 & 0.27 & $-8.56^{* * *}$ \\
Low type/low token vs. Low type/high token & 0.20 & 0.11 & 1.71 \\
Low type/low token vs. High type/low token & 0.21 & 0.12 & 1.78 \\
Low type/low token vs. High type/high token & -0.52 & 0.12 & $-4.25^{* * *}$ \\
Operation Span total score & 0.00 & 0.00 & 0.90 \\
Reading Span total score & 0.04 & 0.00 & $7.34^{* * *}$ \\
Between-condition comparisons & & & \\
High type/high token vs. Low type/high token & 0.78 & 0.12 & $6.38^{* * *}$ \\
High type/high token vs. High type/low token & 0.42 & 0.14 & $3.11^{* *}$ \\
Low type/high token vs. High type/low token & -0.37 & 0.13 & $-2.89 * *$ \\
\hline
\end{tabular}

Note. ${ }^{*} p<.05, * * p<.01,{ }^{* * *} p<.001 . \mathrm{SE}=$ standard error. 
Table 6 Comparison of production accuracy between old and new items and between explicit and incidental learning in each incidental learning condition

\begin{tabular}{lccccc}
\hline Incidental condition & \multicolumn{2}{c}{ Old vs. New } & & \multicolumn{2}{c}{ Explicit vs. Incidental } \\
\cline { 2 - 3 } \cline { 5 - 6 } & $S E$ & Wald $z$ & & $S E$ & Wald $z$ \\
\hline Production of complete endings & & & & & \\
High type/high token & 0.34 & $3.64^{* * *}$ & & 0.05 & $9.85^{* * *}$ \\
Low type/high token & 0.23 & $3.30^{* * *}$ & & 0.07 & $7.52^{* * *}$ \\
High type/low token & 0.24 & $3.22^{* * *}$ & & 0.20 & $7.87^{* * *}$ \\
Low type/low token & 0.20 & $2.70^{* *}$ & & 0.49 & $6.54^{* * *}$ \\
Production of incomplete endings & & & & \\
High type/high token & 0.18 & -1.75 & & 0.15 & $12.37^{* * *}$ \\
Low type/high token & 0.16 & -0.33 & & 0.05 & $6.98^{* * *}$ \\
High type/low token & 1.63 & -0.98 & 0.16 & $5.04^{* * *}$ \\
Low type/low token & 0.16 & 0.08 & 0.46 & $6.04^{* * *}$ \\
\hline
\end{tabular}

Note. ${ }^{*} p<.05, * * p<.01, * * * p<.001 . \mathrm{SE}=$ standard error. 
Table 7 Correlations between two sets of WM scores and production accuracy for complete and incomplete endings in each learning condition

\begin{tabular}{lccccccccc}
\hline Condition & \multicolumn{2}{c}{ Production of complete endings } & \multicolumn{2}{c}{ Production of incomplete endings } \\
\cline { 2 - 9 } & $\begin{array}{c}\text { OS } \\
\text { total }\end{array}$ & $\begin{array}{c}\text { OS } \\
\text { score }\end{array}$ & $\begin{array}{c}\text { RS } \\
\text { total }\end{array}$ & $\begin{array}{c}\text { RS } \\
\text { score }\end{array}$ & $\begin{array}{c}\text { OS } \\
\text { total }\end{array}$ & $\begin{array}{c}\text { OS } \\
\text { score }\end{array}$ & $\begin{array}{c}\text { RS } \\
\text { total }\end{array}$ & $\begin{array}{c}\text { RS } \\
\text { score }\end{array}$ \\
\hline Explicit learning & $0.49^{*}$ & $0.45^{*}$ & 0.29 & 0.16 & $0.50^{*}$ & $0.50^{*}$ & 0.22 & 0.12 \\
High type/low token & 0.20 & 0.03 & 0.26 & 0.31 & 0.33 & 0.13 & 0.38 & $0.45^{*}$ \\
Low type/high token & 0.20 & 0.03 & 0.26 & 0.31 & 0.33 & 0.13 & 0.38 & $0.46^{*}$ \\
High type/high token & 0.42 & 0.42 & 0.35 & $0.46^{*}$ & 0.23 & 0.18 & 0.39 & 0.39 \\
Low type/low token & 0.14 & 0.14 & -0.10 & -0.11 & 0.25 & 0.31 & 0.12 & 0.10 \\
\hline
\end{tabular}

Note. ${ }^{*} p<.05$. OS $=$ Operation Span, RS = Reading Span. 


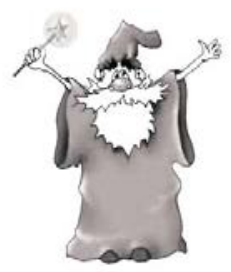

Eto krasniy volshebnik

\section{Idu s krasnim volshebnikom}

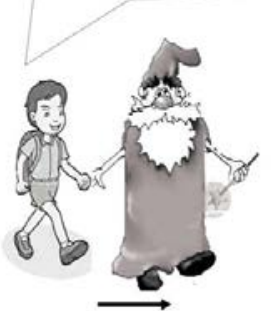

Idu k krasnomu volshebniku

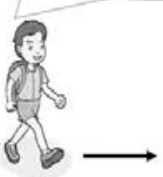

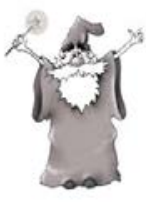

Idu ot krasnogo volshebnika

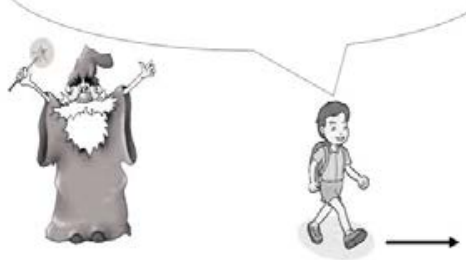

Figure 1 A sample training slide. 


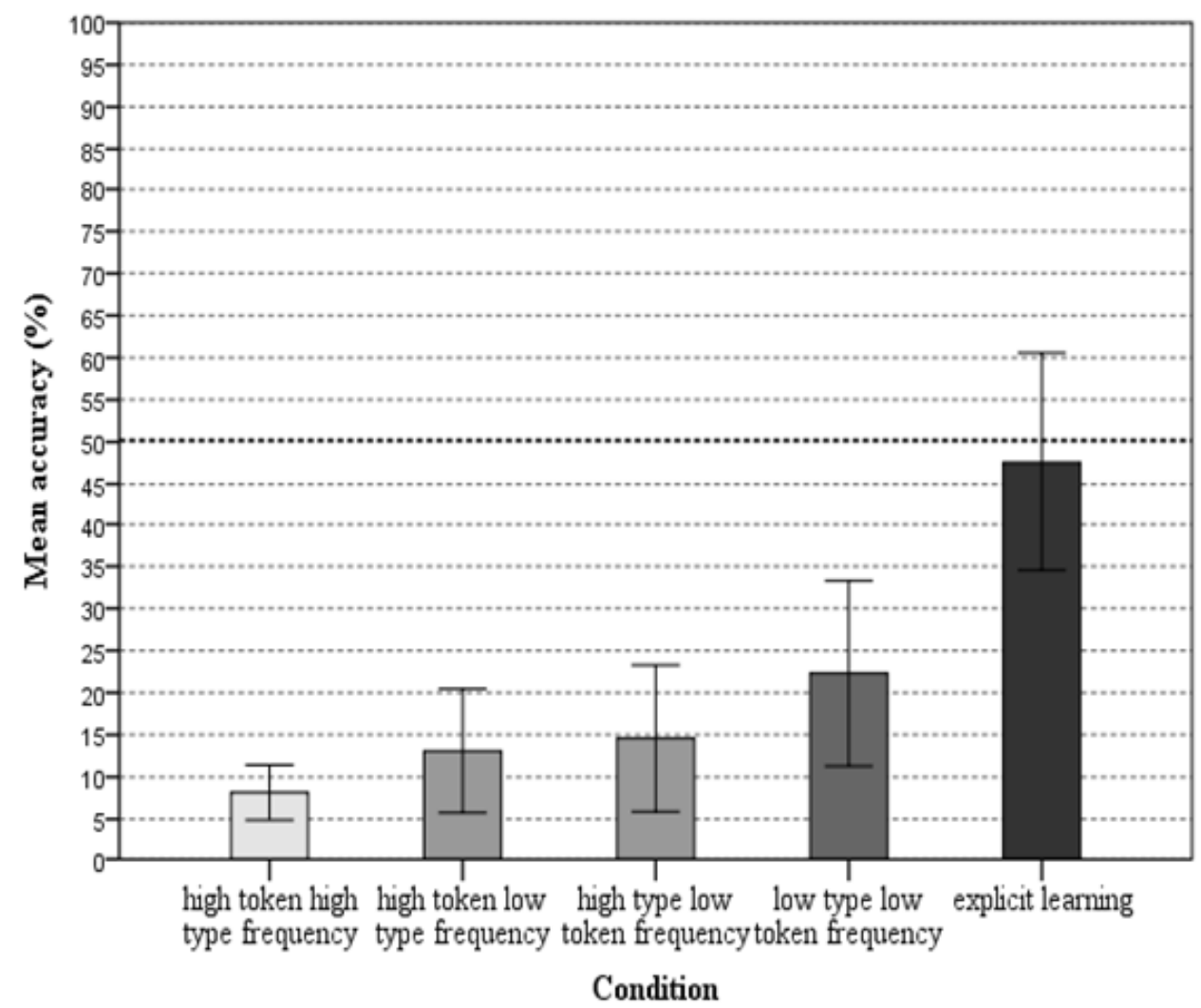

Figure 2 Production accuracy (percent correct) for complete endings across learning conditions. Error bars enclose 95\%CI. 


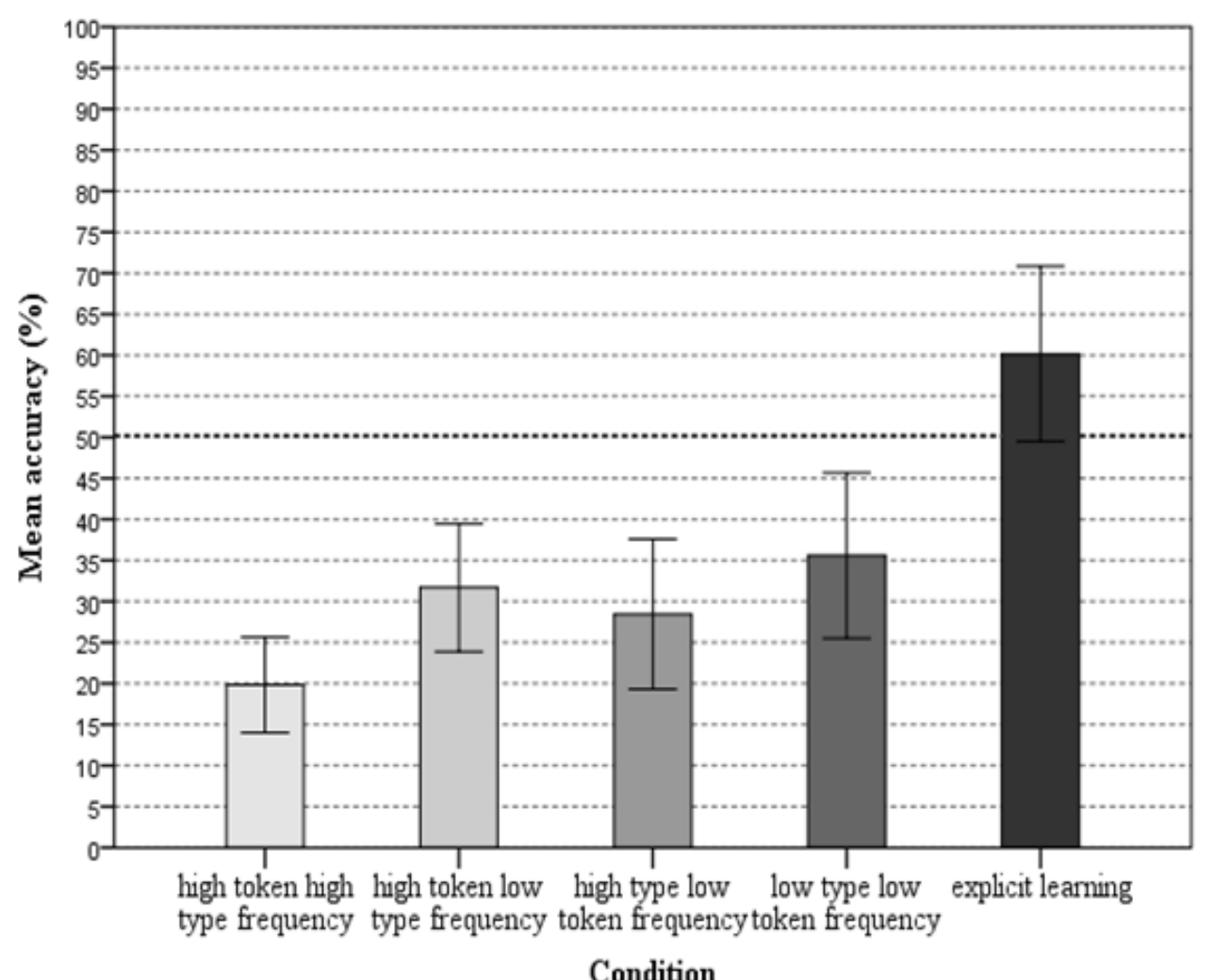

Figure 3 Production accuracy (percent correct) for incomplete endings across learning conditions. Error bars enclose 95\%CI. 